\title{
An Overview of the Recent Salmon Returns in Japan: Poor Returns of Chum and Pink Salmon
}

\author{
Toshihiko Saito \\ Fisheries Resources Institute, Japan Fisheries Research and Education Agency (FRA), 2-2, Nakanoshima, \\ Toyohira-ku, Sapporo, Hokkaido 062-0922, Japan
}

Keywords: adult returns, catch timing, chum salmon, coastal sea surface temperature, oceanic current, Okhotsk coast, Pacific coast, pink salmon

All seven species of anadromous Pacific salmon listed in the NPAFC Convention-chum salmon, Oncorhynchus keta; coho salmon, O. kisutch; pink salmon, O. gorbuscha; sockeye salmon, O. nerka; Chinook salmon, $O$. Tshawytscha; cherry (masu) salmon, O. masou; and steelhead trout, O. mykiss - are caught every year by coastal fisheries in northern Japan. Of these, chum and pink salmon are most commonly caught; for example, chum and pink salmon comprised more than $97 \%$ (93.5\% and $3.7 \%$ by weight, respectively) of the total catch in 2019 , followed by masu salmon (2.7\%) (Ministry of Agriculture, Forestry and Fisheries, Japan 2021). However, chum and pink salmon catches have either declined or been variable in recent years. This study assessed the status of current stocks of Japanese chum and pink salmon and the environmental anomalies that may be affecting salmon stocks.

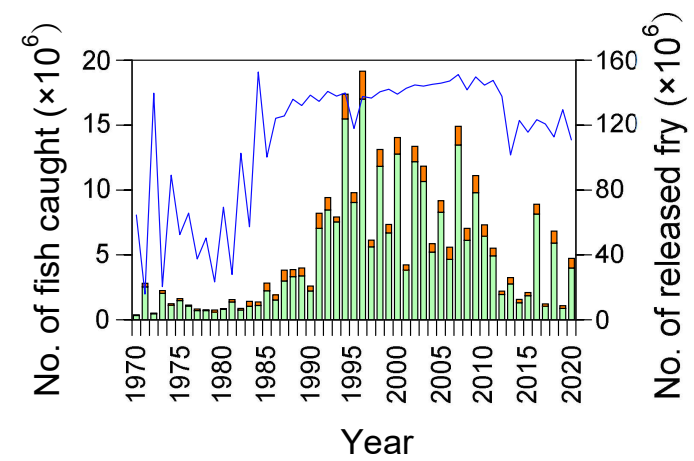

Fig. 1. Coastal catch $\square$, in-river catch $(\square)$ and number of released fry $(-)$ for pink salmon in Japan (1970-2020).

The number of pink salmon released annually from hatcheries in Hokkaido increased markedly in the early 1980s. From the late 1980s to 2012, releases were relatively constant, with an average of 141 million fry released from 1988 to 2012 (Fig. 1). However, from 2013 to the present, the number of fry released has declined to approximately 120 million due to poor adult returns (i.e., coastal catch + in-river catch), which resulted in the lack of broodstock in rivers. Adult returns have also fluctuated markedly since the 1990s, with the relative abundance of pink salmon adult returns shifting occasionally from odd- to even-numbered years and vice versa from 1970 to 2020. From 1970 to 1991, odd-numbered-year lines were generally more abundant than even-numbered-year lines, but the latter were more numerous than the former during 1992-2002. Pink salmon adult returns in odd-numbered years exceeded those in even-numbered years during the period from 2003 to 2015, but the abundance has shifted once again from odd- to even-numbered years from 2016 to the present. From 2003 to 2020, the average number of adult returns of pink salmon in even-numbered years has been relatively stable at 6.6 million fish, except for extremely poor returns in 2012 and 2014 when 2.2 million and 1.6 million fish adults returned, respectively. However, adult returns in odd-numbered years have declined continuously from 14.9 million in 2007 to 1.1 million in 2019. Catch timing of pink salmon in coastal waters, i.e., the $25^{\text {th }}, 50^{\text {th }}$, and $75^{\text {th }}$ percentiles of the cumulative coastal annual catch, typically occurred earlier in odd-numbered years than in even-numbered years from 1989 to 2020. The $50^{\text {th }}$ percentile of the coastal catch timing has been occurring earlier in both odd- and even-numbered years over the same period (Spearman's rank correlation, [odd-numbered years] $\rho=-0.67, p<0.001, n=16$; [evennumbered years] $\rho=-0.68, p<0.001, n=16$ ). Japanese pink salmon return to coastal waters around August when the coastal sea surface temperature (SST) is at its highest. In the coastal waters of the Sea of Okhotsk $\left(44-46^{\circ} \mathrm{N}\right.$, $142-147^{\circ} \mathrm{E}$ ), the SST anomalies (mgd_sst_pac_T provided by the Japan Meteorological Agency) increased from 1989 to 2019 (Spearman's rank correlation, $\rho=0.07, p<0.05, n=1116$ [36 of 10-day average SST/year $\times 31$ years]), and it appears that the earlier catch timing of pink salmon observed in the last three decades may be 
associated with warmer SST conditions along the Okhotsk coast (e.g., Kovach et al. 2012). In addition, it is also possible that the intensive selection for earlier migrants of Japanese pink salmon that occurred by Hokkaido salmon hatcheries during the 1980s and up to the mid-1990s may have influenced this change in catch timing (Saito et al. 2016).

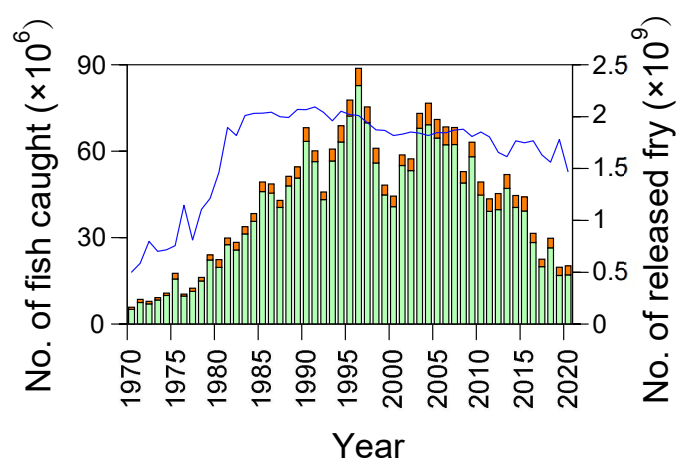

Fig. 2. Coastal catch $(\square)$, in-river catch $(\square)$ and number of released fry $(\longrightarrow)$ for chum salmon in Japan (1970-2020).

The number of chum salmon released annually increased sharply in the 1970s, but it has remained relatively constant since the early 1980s (Fig. 2). The adult returns of chum salmon peaked in 1996, with 89 million fish caught around northern Japan. However, returns of adult chum salmon started declining gradually after the mid2000s, and then more markedly from 2010 to 2015, before being severely reduced to levels last seen in the late 1970s to early 1980s in the last five years (2016 to 2020). The declines observed in adult chum salmon returns have been particularly severe along the Pacific coasts of Hokkaido and Honshu islands (Saito and Miyakoshi 2018). When coastal SSTs increase along the Pacific coasts during March to May, the brood year stocks of chum salmon that experience these warm coastal SST conditions during the early period of their marine lifecycle tend to show better early survival, which results in improved year-class strength as adults (Saito and Nagasawa 2009; Saito and Miyakoshi 2018). The 2012 and 2013 brood years, which experienced cold coastal SSTs during March to May of 2013-2014 followed by higher SSTs during June to July in the same years, showed very poor adult returns during 2016 to 2018 along the Pacific coast (Saito and Miyakoshi 2018). Such abrupt changes in coastal SSTs, from negative anomalies to positive anomalies during March to July of 2013-2014, were believed to have been responsible for the poor adult returns in these brood years (Saito and Miyakoshi 2018). Although abrupt changes in SST were still observed in the spring of 2015 to the early summer, the coastal SSTs along the Pacific coast were higher during March to July in 2016. Given the coastal SST conditions in 2016 and considering the previous findings, the 2015 brood year could have been expected to show better year-class strength as adults. However, adult returns from the 2015 brood year were similar to, or lower than, those of the 2012 and 2013 brood years along the Pacific coast. In particular, the adult returns of the 2015 brood year along the Pacific side of Honshu were extremely low at $12.4 \%$ and $15.6 \%$ of the poor adult returns for the 2012 and 2013 brood years, respectively. During the spring to early summer of 2016, the intensity of the cold Oyashio Current (OY) that flows southward along the Pacific coast off Japan weakened considerably. Unlike the OY, the Tsugaru Warm Current, which originates from the Tsushima Warm Current (TWC) and flows from the Sea of Japan to the Pacific Ocean through the Tsugaru Strait between Hokkaido and Honshu, intensified during the same period. Wagawa et al. (2016) demonstrated that adult return rates of chum salmon in Iwate Prefecture, where the chum salmon catches are typically the highest on the Pacific side of Honshu, were negatively correlated with the ratio of warm (TWC) to cold (OY) water when the chum salmon would have been at the juvenile stage. Although the underlying mechanisms of how the relative ratio of warm to cold water affects juvenile survival in coastal waters are unknown, the extremely poor adult returns of the 2015 brood year may be related to the intensities of the OC and TWC in 2016. Since the trend of a weaker OC and a stronger TWC have continued to some extent from 2016 to the present, there is some concern about the future adult returns of chum salmon along the Pacific coast of northern Japan.

\section{REFERENCES}

Kovach, R.P., A.J. Gharrett, and D.A. Tallmon. 2012. Genetic change for earlier migration timing in a pink salmon population. Proc. R. Soc. B. 279: 3870-3878.

Ministry of Agriculture, Forestry and Fisheries, Japan. 2021. Statistical survey on marine fishery production in 2019. (Available at https://www.maff.go.jp/j/tokei/kouhyou/kaimen_gyosei/) (In Japanese)

Saito, T., and K. Nagasawa. 2009. Regional synchrony in return rates of chum salmon (Oncorhynchus keta) in Japan in relation to coastal temperature and size at release. Fish. Res. 95: 14-27. 
Saito, T., and Y. Miyakoshi. 2018. Current status of chum and pink salmon: what is reducing adult returns in Japan? N. Pac. Anadr. Fish Comm. Tech. Rep. 11: 8-9. (Available at https://npafc.org)

Saito, T., Y. Hirabayashi, K. Suzuki, K. Watanabe, and H. Saito. 2016. Recent decline of pink salmon (Oncorhynchus gorbuscha) abundance in Japan. N. Pac. Anadr. Fish Comm. Bull. 6: 279-296. (Available at https://npafc.org)

Wagawa, T., T. Tamate, H. Kuroda, S. Ito, S. Kakehi, T. Yamanome, and T. Kodama. 2016. Relationship between coastal water properties and adult return of chum salmon (Oncorhynchus keta) along the Sanriku coast, Japan. Fish. Oceanogr. 25: 598-609. 